\title{
Selected technology-critical elements as indicators of anthropogenic groundwater contamination
}

\author{
NITAI AMIEL ${ }^{1}$, ISHAI DROR ${ }^{1}$, ARIK ZURIELI ${ }^{2}$, YAKOV $^{2}$ \\ LIVSHITZ $^{2}$, GUY RESHEF ${ }^{2}$ AND BRIAN BERKOWITZ ${ }^{1}$ \\ ${ }^{1}$ Weizmann Institute of Science \\ ${ }^{2}$ Israel Hydrological Service \\ Presenting Author: nitai.amiel@weizmann.ac.il
}

Groundwater contamination originating from anthropogenic industrial activities is a global concern, adversely affecting natural ecosystems and impacting health of living organisms. Monitoring groundwater contamination is often limited due to poor hydrogeological delineation, so that numerous indicators (organic, inorganic, isotopic) are used simultaneously to reduce uncertainty. We suggest that selected Technology-Critical Elements (TCEs), which are usually found in very low concentrations in groundwater, relative to frequently used indicators, might serve as contamination indicators that can be monitored through aquifer systems. We demonstrate here how Y, $\mathrm{Rh}, \mathrm{Tl}, \mathrm{Ga}$, and Ge can be applied as indicators for monitoring anthropogenic groundwater contamination in two different groundwater systems. Using these TCEs, we identify phosphogypsum ponds located adjacent to two fertilizer plants as sources of groundwater contamination. In addition, we determined the extent of well and spring contamination in the region by monitoring the spatial distribution of the contaminant plume. Results show significant contamination of the groundwater beneath both fertilizer plants, leading to contamination of a series of wells and two natural springs. The water in these springs contains elevated concentrations of toxic metals; $\mathrm{U}$ and $\mathrm{Tl}$ levels, among others, are above the maximum concentration limits for drinking water. 